DOI: $10.35643 /$ Info.26.1.7

Dossier temático: Ética de la Información

\title{
Implicaciones éticas del uso del machine learning como mediador en el desarrollo de habilidades metacognitivas en niños y adolescentes
}

Ethical implications of the use of machine learning as a mediator in the development of metacognitive skills in children and adolescents

Implicações éticas do uso do machine learning como mediador no desenvolvimento de habilidades metacognitivas em crianças e adolescentes

Miguel Ángel Pérez Álvarez ${ }^{\mathrm{a}}$

\footnotetext{
a Colegio de Pedagogía, Facultad de Filosofía y Letras, Universidad Nacional Autónoma de México, Profesor de Tecnologías en la Educación, 04040. ORCID: 0000-0002-4624-7098 Correo electrónico:mapa@unam.mx.
}

\section{Resumen}

El presente artículo revisa un enfoque para el uso del Machine Learning en el desarrollo de habilidades metacognitivas en niños y adolescentes. Se analiza la pertinencia pedagógica y las implicaciones éticas en la introducción de tecnologías digitales emergentes en el ámbito educativo. Señalamos la relevancia de una aproximación pedagógica y ética a las tecnologías digitales que se utilizan en el ámbito educativo para superar las visiones centradas en el aprendizaje exclusivo de la técnica.

Palabras clave: MACHINE LEARNING, INTELIGENCIA ARTIFICIAL; ÉTICA; METACOGNICIÓN; EDUCACIÓN.

\begin{abstract}
This article reviews an approach to the use of Machine Learning in the development of metacognitive skills in children and adolescents. The pedagogical relevance and ethical implications in the introduction of emerging digital technologies in the educational field are analyzed. We point out the relevance of a pedagogical and ethical approach to digital technologies that are used in the educational field to overcome the visions focused on the exclusive learning of the technique.
\end{abstract}

Keywords: MACHINE LEARNING; ARTIFICIAL INTELIGENCE; ETHICS; METACOGNITION; EDUCATION. 


\section{Resumo}

Este artigo revisa uma abordagem para o uso do Aprendizado de Máquina no desenvolvimento de habilidades metacognitivas em crianças e adolescentes. A relevância pedagógica e as implicações éticas na introdução de tecnologias digitais emergentes no campo educacional são analisadas. Ressaltamos a relevância de uma abordagem pedagógica e ética das tecnologias digitais utilizadas no campo educacional para superar as visões voltadas para o aprendizado exclusivo da técnica.

Palavras-chave: MACHINE LEARNING; INTELIGÊNCIA ARTIFICIAL; ÉTICA; METACOGNIÇÃO; EDUCAÇÃO.

Fecha de recibido: $20 / 08 / 2020$

Fecha de aceptado: 02/05/2021

\section{Introducción}

El uso de inteligencia artificial en tareas educativas evidencia la necesidad de reflexionar sobre las implicaciones que tiene el uso de tecnologías en el desarrollo del ser humano. Las tecnologías que favorecen el desarrollo del cuerpo y de la mente humanas constituyen el elemento esencial de la cultura. Representan el símbolo de la transformación del hombre en homo faber. Por ende, su función práctica representa también un elemento de los procesos civilizatorios. La apropiación que hace el hombre del mundo natural de la domesticación de animales o de la construcción de villas y ciudades hasta los viajes a otros planetas, implican el desarrollo de técnicas cada vez más sofisticadas y complejas. Este desarrollo técnico permite construir una cultura y una visión del hombre como ser educable, como "ser para la tecnología". Nuestra cultura, de menos de dos mil años, se fija como deber el aprender y utilizar las herramientas y dispositivos de la técnica. ¿Cuáles son las implicaciones que tiene en la existencia humana el considerar un deber el usar y aprender a usar los elementos de la técnica? ¿Hay un imperativo ético en el uso de las tecnologías digitales?

Hace cuatro décadas se introdujeron las primeras computadoras personales en las escuelas de educación básica en México. Algunas escuelas privadas, así como algunos proyectos piloto en escuelas públicas, probaron con la creación de 
laboratorios de cómputo en los que se enseñaban los rudimentos del manejo de sistemas operativos y las aplicaciones tradicionales de ofimática. De manera aún experimental, se inició el uso de la programación para favorecer el pensamiento computacional. El uso de Logo Writer brindó la oportunidad de probar el coding como un medio para el uso de la programación en el desarrollo de habilidades intelectuales. Pocos años más tarde, se introdujeron en las escuelas robots de Lego para combinar la programación con Logo Writer y ampliar las posibilidades del uso de tecnologías digitales en las aulas.

Cuando a principios de la década, en 2010, se hizo accesible al público en general el uso de la inteligencia artificial por parte de empresas como IBM y Google, los educadores tuvimos la oportunidad de utilizar esa tecnología para contribuir a mejorar las capacidades de nuestros estudiantes como la evaluación de las estrategias personales en tareas intelectuales, la resolución de problemas, el análisis y sistematización de información, etcétera. Al uso de la programación y al diseño de algoritmos para los robots, se sumó el entrenamiento de máquinas o Machine Learning.

Las ideas pedagógicas de autores como Jean Piaget (1971), Lev Vigotsky (1978) y J. Flavell (1979) orientan nuestro trabajo de análisis pedagógico sobre las oportunidades que ofrece el entrenamiento de máquinas en el desarrollo de habilidades metacognitivas. Tenemos la intención de superar las ideas tecnocéntricas que consideran que la tecnología debe usarse simplemente porque está disponible. Queremos mostrar que es necesario contar con un sustento pedagógico en la introducción de cualquier tecnología en el aula. Nuestra segunda preocupación es determinar las implicaciones éticas de la interacción educativa entre niños y adolescentes con tecnologías que realizan tareas esperadas para ser llevadas a cabo por seres humanos, como es el caso de la inteligencia artificial. Para ello nos basamos en las ideas de Jean Piaget (1971) y de L. Kohlberg (1971)

\section{Objetivos}

En los últimos tres años hemos probado con los estudiantes de Pedagogía de la UNAM el uso de coding, la robótica y el machine learning en la mediación del aprendizaje. Nuestro principal foco de atención ha sido la evaluación del 
pensamiento algorítmico como medio para el desarrollo de habilidades metacognitivas. Esta posibilidad la habíamos probado desde 1990 haciendo uso del coding con programas como Logo Writer, Scratch y Lego WeDo. Así que ampliamos el horizonte con el uso del programa "Machine Learning for Kids" y del programa Teachable Machine.

Desarrollar el criterio moral mediante la reflexión de niños y adolescentes respecto a los bias que se suscitan en el diseño de algoritmos.

\section{Metodología}

Una de las primeras actividades que realizamos consiste en familiarizar a los estudiantes con las diversas aplicaciones que la IA tiene en actividades cotidianas. Tomamos un juego de memoria desarrollado por el MIT que permite a los niños identificar los datos y los productos de las diversas aplicaciones de IA. La intención es que los estudiantes de todos los niveles, en particular los de la educación básica (K-9), identifiquen la presencia de la Inteligencia Artificial en procesos que les son familiares y la forma en la que opera en diversos dispositivos empleados en su vida cotidiana.

La idea central fue generar algunos módulos mediante un programa que permitiera a los estudiantes de educación básica (el quinto grado de educación primaria) resolver retos de alta demanda cognitiva como entrenar a una máquina (machine learning) para identificar números primos o calcular el valor de fracciones de una recta. Los estudiantes ponen en juego sus conocimientos sobre el tema para entrenar a la máquina a resolver retos de matemáticas.

Esta es una actividad muy importante desde el punto de vista pedagógico, pues el alumno debe construir nociones matemáticas esenciales para poder entrenar a la máquina. Una vez creado el módulo con "Machine Learning for kids" se exporta a Scratch, un lenguaje de programación desarrollado por Mitch Resnick del Life long learning Lab del MIT. Scratch es un lenguaje que se programa con bloques de una manera similar a colocar las piezas en un proyecto de Lego. Los programas que se crean pueden utilizarse en diferentes tareas, incluso pueden utilizarse para programar robots de Lego WeDo. Una vez que los alumnos generan los módulos con el Machine learning for kids, pueden crear algoritmos con los bloques de 
Scratch y entrenar a la máquina para probar si su algoritmo es exitoso al resolver los retos intelectuales que se les han presentado. En resumen se utiliza el aprendizaje de máquinas y el desarrollo de algoritmos para favorecer la construcción de nuevos conocimientos y el desarrollo de habilidades metacognitivas como la autorregulación de los propios procesos intelectuales.

Hemos utilizado también la herramienta Teachable Machines para que los estudiantes puedan entrenar a un sistema que identifica tanto imágenes como sonidos. El sistema requiere que se den al menos 25 ejemplos de imágenes antes de poder distinguir al menos entre dos distintos especímenes. La capacidad de discriminación es muy grande y es útil para que los participantes comprendan el valor del entrenamiento de máquinas. Al presentar, por ejemplo, imágenes de algunos animales o el mapa de algunas zonas geográficas se movilizan conocimientos previos y genera procesos de investigación sobre temas curriculares.

Cuando reflexionamos con los estudiantes sobre el valor de colaborar con una máquina en una tarea que se espera sea realizada por un ser humano, tenemos oportunidad para que valoren la trascendencia de esta tecnología en el futuro de nuestra vida cotidiana y sobre la responsabilidad que se adquiere con su uso para fines ilegales. Introducimos en todos los casos una reflexión de naturaleza ética en su uso.

\section{Resultados}

Nuestra experiencia ha sido muy positiva y hemos determinado que, al afrontar retos mediante la programación de algoritmos, los estudiantes desarrollan habilidades intelectuales y construyen conocimientos. Entre las habilidades metacognitivas más relevantes está la ya mencionada autocorrección de procesos. Los estudiantes prueban sus algoritmos en Scratch y evalúan el desempeño del sistema para resolver los problemas. Si encuentran que el sistema tiene fallas, llevan a cabo la corrección y optimizan el algoritmo.

Después de varias iteraciones, los estudiantes evalúan su propia capacidad para entrenar a la máquina. Hemos aprovechado estos procesos para hablar sobre los 
prejuicios raciales implícitos en algunos sistemas autónomos de reconocimiento facial o del lenguaje natural

Como hemos explicado antes, el uso del pensamiento computacional para el desarrollo de habilidades intelectuales y la construcción de conocimientos, se ha visto enriquecido con el uso del machine learning. Hay otras experiencias con Teacheable Machine en las que utilizamos el machine learning en el reconocimiento de lenguaje natural y de imágenes, con el mismo propósito con el que usamos el coding y la robótica.

La revisión de aspectos éticos es parte de la actividad de las clases y nos interesa favorecer el desarrollo del criterio ético como establecen en sus teorías tanto Jean Piaget como Kohlberg. Según estos autores, el desarrollo del criterio ético es resultado de un desarrollo en el que los seres humanos pasan de la heteronomía del niño pequeño a la autonomía del joven adulto. Ese desarrollo sólo es factible si los estudiantes viven un proceso gradual de responsabilización de su conducta, de un ejercicio paulatino y gradual de la libertad personal. Este desarrollo implica el uso de la reflexión y de la ética crítica. Colaborar con inteligencia artificial para entrenarla en la realización de tareas pensadas para humanos acarrea temas que son materia para ese ejercicio reflexivo.

\section{Discusión}

Las preguntas que emergen son, sin duda, relativas a la pertinencia de acercar a los chicos a la interacción con la inteligencia artificial (IA). Las dudas nacen de la sensación que algunos niños tienen de la inteligencia artificial como "alguien", como un sujeto independiente, que cuenta con personalidad.

Las implicaciones éticas cuando los niños y jóvenes interactúan con un agente no humano plantea la pregunta relativa a la pertinencia de exponer a un menor a la lógica de "pensamiento" de un agente de esta naturaleza. ¿este agente responde a un algoritmo que está descargado de prejuicios raciales, de género, etcétera. Alimentar los procesos reflexivos en su dimensión ética parece imprescindible al trabajar con inteligencia artificial en clase. 
Nuestra propia reflexión como educadores nos lleva a preguntarnos sobre el sentido de la inteligencia artificial en lo relativo a la pertinencia de su uso educativo. En este escenario la inteligencia artificial puede ser definida como un objeto técnico al interior del aula. Simondon (2014) ha dicho con respecto al objeto técnico:

Como un objeto de uso, el objeto técnico implica distribución, reparación, reventa, por lo que las diversas relaciones de dependencia entre productores, distribuidores, usuarios con aspectos y representaciones particulares relativas a los mercados extranjeros, envejecimiento, los cambios en valor del objeto (nuevo, obsoleto, pasado de moda, viejo, muy poco frecuente). El ser técnico deviene objeto no solo porque es material, sino también porque está rodeado por un halo de la sociabilidad; no hay ningún objeto que sea puramente objeto de uso, está también parcialmente sobre determinado como símbolo psicosocial. [Trad. mía] [1]

Este símbolo psico social en el que se convirtieron las computadoras personales, la Internet, la robótica y otras tecnologías de la mente es el destino de la inteligencia artificial. Hay en nuestro tiempo la necesidad social de utilizar la tecnología más reciente, la más popular. Se concibe como un "algo" que debe ser usado

Según ha establecido Bernard Stiegler (2012) en su conferencia "Estado de choque. Tontería y saber":

Un ser humano sin técnica no es viable, no puede sobrevivir y vive en una situación que llamamos desde hace un siglo "neotécnica". Es un ser expulsado prematuramente y tiene que continuar su organización, completar su organismo con órganos artificiales. [2]

Aunque sea usado de cualquier manera, la inteligencia artificial es concebida como algo que debe ser utilizado: centrado en su tecnicidad y sin la mínima reflexión pedagógica y ética de su uso, la insertamos en la práctica docente sin una mínima consideración de naturaleza educativa y sin una reflexión educativa del mensaje implícito en su aplicación.

H. Ozbekhan (1967) en su trabajo The Triumph of Technology.: Can implies Ought[3] establece que en nuestro mundo diseñado, la realidad tecnológica indica que "el podemos hacerlo" se toma en el sentido "debemos hacerlo". Por ello la experiencia del cambio y la adopción de nuevas tecnologías impacta en nuestra vida cotidiana en la medida que nos vislumbramos como seres marginales si no 
tenemos acceso a las nuevas tecnologías o si no somos capaces de utilizarlas, pues faltamos al principio ético dominante en nuestro tiempo en el que el "debemos adoptar y utilizar con esas tecnologías". La principal brecha no es digital sino existencial y ética. La cultura digital impone este principio ético dominante como base de la conducta social.

Stiegler ha señalado que en el uso de la tecnología por la tecnología prevalece la "tontería": Stiegler denomina "tontería sistémica" a:

La tontería nos llega a todos y permanentemente podemos observarla muy concretamente cuando nos subimos al auto. Cuando nos ponemos al volante y arrancamos y circulamos por una calle de París nos transformamos en tontos, a veces en locos, y ni siquiera nos damos cuenta. En realidad, estamos atrapados en dispositivos como los llamaban Foucault o Deleuze que modifican nuestro comportamiento y no caemos en la cuenta de ello.[4]

Resulta pues imprescindible hacer un alto y meditar sobre nuestra tontería. Es necesario que la reflexión de naturaleza pedagógica y la ética crítica se transformen en el imperativo educativo al introducir de los modelos de inteligencia artificial como mediadores del aprendizaje. Superar la tontería que concibe el uso de la AI y de otras tecnologías como una vía para superar la marginalidad. Debemos hacer un estudio más profundo de las implicaciones en materia de desarrollo intelectual, de las estrategias de resolución de problemas, de la colaboración con la inteligencia artificial como parte de un andamiaje cognitivo, como un elemento complementario de nuestra necesidad de comprender y crecer como seres humanos. Partir de una crítica de la tontería sistémica para desarrollar una visión educativa y pedagógica bien fundada en la reflexión ética que haga de la inteligencia artificial emergente un nuevo elemento para el desarrollo libre y responsable de los seres humanos.

\section{Bibliografía}

Flavell, J. H. (1979). Metacognition and cognitive monitoring: A new area of cognitive-developmental inquiry. American Psychologist, 34, 10, 906911. https://doi.org/10.1037/0003-066X.34.10.906

Kohlberg L. (1971). Moral Stages and moralizations. En: Lickona, T. Moral development and behavior. New York: Holt.

Kohlberg L. (1974). The development of modes moral thing and choice years ten to sixteen. University of Chicago. 
Ozbekhan, H. (1967). The Triumph of Technology: 'Can' Implies 'Ought'. Santa Monica, California: System Development Corp.

Piaget, J. (1971). El criterio moral del niño. Madrid: Fontanella.

Simondon, G. (2014). "Psycosociologie de la technicité" en Sur la technique (1953-1983). Paris: Press Universitaires de France.

Stiegler, B. (2012). La Tontería. En: Conferencia "Encuentros y debates Autrement" Estados de choque. Tontería y saber en el s. XXI. Sala Jean Dame, París. Disponible en: https://youtu.be/FCf-S8mQSZk (consultado diciembre 2017).

Vygotsky, L. S. (1978). Mind in Society. Cambridge, MA: Harvard University Press.

\section{Notas}

[1] G. Simondon "Psycosociologie de la technicité" en Sur la technique (19531983), Press Universitaires de France, París, 2014. P. 28 [“En tant qu'objet d'usage, l'objet technique implique distribution, réparations, reventes, donc relations de dépendances diverses entre producteurs, concessionnaires, utilisateurs, avec les aspects particuliers et les représentations relatives aux marchés étrangers, au vieillissement, aux changements de valeur de l'objet (neuf, périmé, démodé, ancien, très rare). L'être technique devient objet non pas seulement parce qu'il est matériel, mais aussi parce qu'il est entouré d'un halo de socialité; aucun objet n'est purement objet d'usage, il est toujours partiellement surdéterminé comme symbole psychosocial”. Trad. mía]

[2] B. Stiegler, La Tontería. Conferencia dictada dentro del ciclo "Encuentros y debates Autrement" a propósito de la publicación de su libro Estados de choque. Tontería y saber en el s. XXI, Sala Jean Dame, París, Miércoles 25 de enero de 2012. Véase https://youtu.be/FCf-S8mQSZk (consultado diciembre 2017)

[3] Ozbekhan, H., The Triumph of Technology: 'Can' Implies 'Ought', System Development Corp, Santa Monica, California, 1967.

[4] B. Stiegler, conferencia mencionada: 2012

\section{Author contribution}

The entirety of this manuscript was prepared by Miguel Ángel Pérez Álvarez.

\section{Editor's notes}

The editor responsible for the publication of this article was Rafael Capurro. 